\title{
IMAGING OF INTRACRANIAL TUMOURS WITH HISTOPATHOLOGICAL CORRELATION
}

\author{
Jamkhana Abdul Gafoor'1, Onteddu Joji Reddy², Balla Suresh ${ }^{3}$, D. Harinath4 ${ }^{4}$ Bandi Arun Kumar 5 \\ 1 Professor, Department of Radiodiagnosis, Kurnool Medical College, Kurnool. \\ ${ }^{2}$ Professor and HOD, Department of Radiodiagnosis, Kurnool Medical College, Kurnool. \\ ${ }^{3}$ Associate Professor, Department of Radiodiagnosis, Kurnool Medical College, Kurnool. \\ ${ }^{4}$ Assistant Professor, Department of Radiodiagnosis, Kurnool Medical College, Kurnool. \\ ${ }^{5}$ Senior Resident, Department of Radiodiagnosis, Kurnool Medical College, Kurnool.
}

\begin{abstract}
\section{BACKGROUND}

Although CNS tumours are not common $(<1.5 \%$ of all cancers) in comparison with tumours of other organs (e.g., lung, breast, or colon), they deserve a unique position in tumour oncology because of their histopathologic complexity and biologic behaviour. Topographical and histological classifications, as well as correlations of topography to pathology, serve for the better studying, understanding, and handling of brain tumours.

Aim- This study was undertaken to study the imaging findings of intracranial tumours and to compare them with the histopathological diagnosis.
\end{abstract}

\section{MATERIALS AND METHODS}

This is a prospective study, a minimum of 50 patients with signs and symptoms of intracranial tumours referred to the Department of Radiodiagnosis in Kurnool Medical College.

All the patients with suspected intracranial tumours underwent Plain and Contrast Computed tomography of Brain on 16 slice GE bright speed CT.

Plain and contrast MRI was done for all the patients on XGY 0.35 Tesla.

Histopathology examination was done by using Haematoxylin \& Eosin stain in the Department of Pathology, Kurnool Medical College.

Inclusion Criteria- Patients with signs and symptoms of intracranial tumours between all the age groups are included.

Exclusion Criteria- Patients for whom CT or MRI could not be performed due to raised serum creatinine levels, pregnancy, claustrophobia, metal implants and cardiac pacemakers. Patients for whom surgery or HPE was not done are excluded.

\section{RESULTS}

In the present study out of 50 cases, meningiomas accounted for 18 cases, followed by Astrocytomas accounting for 17 cases and Schwannoma and Tuberculomas with 3 cases each. There are 2 cases of Pituitary macroadenoma, 2 cases of craniopharyngioma, one case of oligoastrocytoma, oligodendroglioma/Subependymoma, secondaries, medulloblastoma each. The Sensitivity, Specificity, Positive predictive value, Negative predictive value and p value of CT are $95.35 \%, 28.57 \%, 89.13 \%$, and $50 \%, 0.03$ (significant) respectively. The Sensitivity, Specificity, Positive predictive value, Negative predictive value and p value of MRI are 97.78\%, 40\%, 93.16\%, 66\%, 0.0007 (significant) respectively.

\section{CONCLUSION}

Imaging plays an important role in the diagnosis of intracranial tumours. Compared to CT, MRI has a greater role in accurately diagnosing the intracranial tumours with few false negative and false positive cases.

\section{KEYWORDS}

Computed Tomography, Magnetic Resonance Imaging, Intracranial Tumours, Histopathology.

HOW TO CITE THIS ARTICLE: Gafoor JA, Reddy OJ, Suresh B, et al. Imaging of intracranial tumours with histopathological correlation. J. Evolution Med. Dent. Sci. 2017;6(82):5768-5771, DOI: 10.14260/jemds/2017/1251

\section{BACKGROUND}

Brain tumour is a most dramatic form of illness of humankind. Imaging especially MRI plays a significant role not only in the diagnosis but also in the prognostication of the tumours.

'Financial or Other Competing Interest': None.

Submission 23-08-2017, Peer Review 29-09-2017,

Acceptance 05-10-2017, Published 12-10-2017.

Corresponding Author:

Dr. Jamkhana Abdul Gafoor,

H. No. 49-1-73, Maddurnagar,

Kurnool-518002, Andhra Pradesh,

India.

E-mail: jamkhana@gmail.com

DOI: $10.14260 /$ jemds $/ 2017 / 1251$

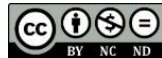

Aside from the initial recognition and characterisation of these lesions (i.e., intra- vs. extra axial, neoplastic vs. nonneoplastic, pathologic type, benign vs. malignant, primary vs. metastatic, and grade of malignancy), the mechanical effects and structural deformities resulting from intracranial neoplasms are also of great importance because the cranium has extremely limited compliance to accommodate increased intracranial pressure.

Although MR imaging has delivered remarkable advances in the information available from the vast array of pulse sequences and MR imaging techniques, the radiologist should still rely most heavily on traditional, more fundamental criteria, such as location in the neuraxis and the age of the patient, for specific pathologic diagnoses. 


\section{Aims and Objectives}

The present study was done to know the sensitivity and specificity of CT \& MRI in diagnosis which is the gold standard for diagnosing intracranial tumours.

\section{MATERIALS AND METHODS}

This is a prospective study involving 50 patients with signs and symptoms of intracranial tumours who were admitted in the Department of Neurosurgery, Kurnool Medical College, Andhra Pradesh.

The study was done for a period of 2 years from October 2014 to October 2016.

\section{Method of Collection of Data \\ Inclusion Criteria}

Patients with signs and symptoms of intracranial tumours between all the age groups are included.

\section{Exclusion Criteria}

Patients for whom CT or MRI could not be performed due to raised serum creatinine levels, pregnancy.

Patients for whom surgery or HPE was not done are excluded.

All the patients with suspected intracranial tumours underwent Plain and Contrast Computed tomography of Brain on 16 Slice G Bright Speed CT.

Plain and contrast MRI was done for all the patients on XGY 0.35 Tesla.

Histopathology examination was done postoperatively by using Haematoxylin \& Eosin stain in the Department of Pathology, Kurnool Medical College.

Number of Patients Included: 50.

\section{Justification of Sample Size}

All the patients with suspected clinical diagnosis of intracranial tumour from the period of 2 years from October 2014 to October 2016. A total of 50 patients were included.

\section{Study Involves}

Humans only.

\section{Type of Study}

Descriptive study.

Collected data was analysed by comparing it with histopathology to know sensitivity, specificity, positive predictive value, negative predictive value and diagnostic accuracy of the imaging modalities.

\section{RESULTS}

In this prospective study involving 50 patients, 5 cases $(10 \%)$ are below the age of 20 years, 18 cases (36\%) are between the age group 20-40 years, and 27 cases (54\%) are seen in patients of age above 40 years (Table 1 ).

Among 50 patients, 19 were male and 31 were female (Table 1).

Among 50 cases in the present study, Meningiomas accounted for 18 cases, followed by Astrocytomas accounting for 17 cases and Schwannoma and Tuberculomas with 3 cases each ,2 cases of Pituitary macroadenoma, 2 cases of Craniopharyngioma, one case of oligoastrocytoma, oligodendroglioma/Subependymoma, secondaries, medulloblastoma each (Table 2).
In present study of 50 patients, 38 patients have supratentorial distribution whereas remaining 12 have an infratentorial distribution (Table 2).

Out of 50 cases, 41 cases are correctly diagnosed on CT, 7 cases are incorrectly diagnosed (Table 4).

Out of 7 cases which are incorrectly diagnosed on CT, 5 cases are false positives and 2 cases are false negatives.

Out of the 50 cases, MRI has diagnosed 44 cases correctly and 4 cases have been diagnosed incorrectly on MRI (Table 5).

The Sensitivity, Specificity, Positive predictive value, Negative predictive value and p value of CT are $95.35 \%$, 28.57\%, 89.13\%, and 50\%, 0.03 (significant) respectively.

The Sensitivity, Specificity, Positive predictive value, Negative predictive value and $\mathrm{p}$ value of MRI are $97.78 \%$, 40\%, 93.16\%, 66\%, 0.0007 (Significant) respectively.

\begin{tabular}{|c|c|c|}
\hline Measure & Number & Percentage \\
\hline $\begin{array}{c}\text { Minimum age 3 } \\
\text { Maximum age 70 } \\
\text { Mean age 40.3125+14.77 }\end{array}$ & & \\
\hline Sex & 19 & \\
Male & 31 & 38 \\
Female & & 62 \\
\hline Age Groups (years) & 5 & 10 \\
$<20$ & 18 & 36 \\
$20-40$ & 27 & 54 \\
$>40$ & & \\
\hline
\end{tabular}

Table 1. Descriptive Statistics of Patient's Demography

\begin{tabular}{|c|c|}
\hline Tumour & Number \\
\hline Grade II astrocytoma & 6 \\
\hline Grade III astrocytoma & 5 \\
\hline Glioblastoma multiforme & 6 \\
\hline Oligodendroglioma/Subependymoma & 1 \\
\hline Meningioma & 18 \\
\hline Schwannoma & 3 \\
\hline Pituitary macroadenoma & 2 \\
\hline Craniopharyngioma & 2 \\
\hline Medulloblastoma & 1 \\
\hline Central neurocytoma & 1 \\
\hline Tuberculoma & 3 \\
\hline Secondaries & 1 \\
\hline Oligoastrocytoma & 1 \\
\hline Table 2. Distribution of CNS Tumours According to \\
\hline \multicolumn{2}{|c|}{ Histopathology } \\
\hline
\end{tabular}

\begin{tabular}{|c|c|}
\hline Compartment & Number \\
\hline Supratentorial & 38 \\
\hline Infratentorial & 12 \\
\hline Table 3. Supratentorial and Infratentorial wise \\
Distribution of CNS Tumours \\
\hline
\end{tabular}

\begin{tabular}{|c|c|c|c|}
\hline & \multicolumn{2}{|c|}{ HPE } \\
\hline & & Positive & Negative \\
\hline \multirow{2}{*}{ CT } & Positive & 41 & 5 \\
\hline & Negative & 2 & 2 \\
\hline \multicolumn{4}{|c|}{$\begin{array}{c}\text { Table 4. Comparison of CT Diagnosis with } \\
\text { Histopathological Diagnosis }\end{array}$} \\
\hline
\end{tabular}




\begin{tabular}{|c|c|c|c|}
\hline \multicolumn{2}{|c|}{} & \multicolumn{2}{|c|}{ HPE } \\
\cline { 3 - 4 } \multicolumn{2}{|c|}{} & Positive & Negative \\
\hline \multirow{3}{*}{ MRI } & Positive & 44 & 3 \\
\cline { 2 - 4 } & Negative & 1 & 2 \\
\hline \multicolumn{3}{|c|}{ Table 5. Comparison of MRI Diagnosis with } \\
Histopathological Diagnosis
\end{tabular}

\section{DISCUSSION}

In the present study out of 50 cases, 5 cases (10\%) are below the age of 20 years, 18 cases (36\%) are between the age group 20-40 years, and 27 cases (54\%) are seen in patients of age above 40 years.

According to Merchant TE et al, approximately 20,500 primary brain tumours are diagnosed in the United States each year, and of these, 3,750 (or 18.3\%) occur in patients less than 19 years of age. ${ }^{1}$

According to Scott et al, $80 \%$ to $85 \%$ of all intracranial tumours occur in adults.

Among the patients aged below 20 years, there are 2 cases of craniopharyngioma, 1 case of Medulloblastoma, Tuberculoma, Ependymoma/Oligodendroglioma each.

Only $1 \%$ to $2 \%$ of all brain tumours occur in children under 2 years of age which include primitive neuroectodermal tumour, teratoma, astrocytoma and choroid plexus carcinoma.

Approximately, half of all intracranial neoplasms in children are gliomas; $15 \%$ are Primitive neuroectodermal tumours including medulloblastoma, ependymoma and craniopharyngioma account for about $10 \%$ each. ${ }^{2,3}$.

Embryonal/primitive neuroectodermal/medulloblastoma and pilocytic astrocytomas are the most common tumours before age 9 years, and gliomas grade I to III between 10 and 19 years are common. ${ }^{4}$

In patients aged between 20 and 40 years, Meningiomas accounted for 7 cases, Astrocytomas accounted for 6 cases, Schwannomas for 3 cases, Tuberculomas for 2 cases.

In patients aged above 40 years, Astrocytomas accounted for 12 cases, Meningiomas for 11 cases, Pituitary macroadenomas accounted for 2 cases, Central neurocytoma and secondaries accounted for 1 case each.

Approximately, $50 \%$ of the intracranial tumours are gliomas. Most of them (70\%) are astrocytic tumours, and more than $50 \%$ of these are anaplastic or Glioblastoma Multiforme. ${ }^{5}$

Approximately, $15-20 \%$ of primary tumours in adults are meningiomas, most of them (75\%) found supratentorially. ${ }^{6}$

Out of 50 cases, 41 cases are correctly diagnosed on CT, 7 cases are incorrectly diagnosed (Table 6).

Out of 7 cases which are incorrectly diagnosed on CT, 5 cases are false positives and 2 cases are false negatives.

\begin{tabular}{|c|c|}
\hline CT Diagnosis & Histopathological Diagnosis \\
\hline Metastasis & Grade III Astrocytoma \\
\hline Meningioma & Oligoastrocytoma \\
\hline Cerebral abscess & Grade III Astrocytoma \\
\hline GBM & Tuberculosis \\
\hline Choroid plexus carcinoma & Craniopharyngioma \\
\hline Choroid plexus carcinoma & Glioblastoma multiforme \\
\hline Acute infarct & Grade II glioma \\
\hline
\end{tabular}

\begin{tabular}{|c|c|c|}
\hline & $\begin{array}{c}\text { Present } \\
\text { Study }\end{array}$ & $\begin{array}{c}\text { Taghipour } \\
\text { Zahir et al }\end{array}$ \\
\hline Sensitivity & $95.35 \%$ & $83 \%$ \\
\hline Specificity & $28.57 \%$ & $10 \%$ \\
\hline Positive predictive value & $89.13 \%$ & $93 \%$ \\
\hline Negative predictive value & $50 \%$ & $3 \%$ \\
\hline Accuracy & $86 \%$ & $78 \%$ \\
\hline
\end{tabular}

Table 7. Comparison of CT in Present Study with Other Studies

The Sensitivity, Specificity, Positive predictive value, Negative predictive value and p value of CT are $95.35 \%$, $28.57 \%, 89.13 \%$, and 50\%, 0.03 (significant) respectively.

According to a study done by Taghipour Zahir et al, ${ }^{7}$ the Sensitivity, Specificity, Positive predictive value, Negative predictive value of CT for the diagnosis of CNS tumours was $83 \%, 10 \%, 93 \%, 3 \%$ respectively.

In the present study, the diagnosis was incorrectly made for five cases of gliomas, where two cases of Grade III Astrocytoma were wrongly diagnosed as cerebral abscess and Metastasis respectively, one case of Grade II astrocytoma was wrongly diagnosed as acute infarct, one case of Oligoastrocytoma was wrongly diagnosed as Meningioma, one case of GBM was wrongly diagnosed as Choroid plexus carcinoma.

In 1979, Kendall et al $^{8}$ highlighted the difficulties and pitfalls of diagnosing malignant gliomas on CT scan appearances alone.

They noted that of 314 patients with tumours of known histology, $12.7 \%$ were misdiagnosed, and in $6-5 \%$ a benign lesion was incorrectly reported as malignant. Baker et $\mathrm{al}^{9}$ looked at the false-positive and false-negative rate in the interpretation of nearly 3,000 scans.

In their series, 13 out of 464 (2.8\%) of non-neoplastic lesions were diagnosed as "neoplasms". In 80 of the 1071 (7$5 \%)$ neoplasms, the neuroradiologists failed to diagnose the histological type.

Out of the 50 cases, MRI has diagnosed 44 cases correctly and 4 cases have been diagnosed incorrectly on MRI (Table 8).

The Sensitivity, Specificity, Positive predictive value, Negative predictive value and p value of MRI are $97.78 \%$, $40 \%, 93.16 \%, 66 \%, 0.0007$ (significant) respectively.

\begin{tabular}{|c|c|}
\hline MRI diagnosis & Histopathological diagnosis \\
\hline Metastasis & Grade III astrocytoma \\
\hline High-grade glioma & Oligoastrocytoma \\
\hline Tuberculosis & Glioblastoma multiforme \\
\hline High-grade glioma & Tuberculosis \\
\hline Table 8. False Positives and False Negatives on MRI \\
\hline
\end{tabular}

\begin{tabular}{|c|c|c|}
\hline & $\begin{array}{l}\text { Present } \\
\text { Study }\end{array}$ & $\begin{array}{l}\text { Taghipour } \\
\text { Zahir et al }\end{array}$ \\
\hline Sensitivity & $97.78 \%$ & $92 \%$ \\
\hline Specificity & $40 \%$ & $25 \%$ \\
\hline Positive predictive value & $93.16 \%$ & $93 \%$ \\
\hline Negative predictive value & $66 \%$ & $2 \%$ \\
\hline Accuracy & $94 \%$ & $87 \%$ \\
\hline \multicolumn{3}{|c|}{$\begin{array}{l}\text { Table 9. Comparison of MRI in Present Study } \\
\text { with Other Studies }\end{array}$} \\
\hline
\end{tabular}




\section{CONCLUSION}

Radiology has always been pivotal in the diagnosis and management of central nervous system (CNS) neoplasms.

The main imaging modality of choice is MRI.

The conventional MRI can help in arriving at diagnosis in most of the cases, but still advanced MR imaging modalities play a crucial role in certain situations such as grading of gliomas, differentiating a GBM from tuberculoma, high-grade glioma from cerebral abscess and vice versa and the differentiation is very important as the treatment provided greatly differs and from prognosis point of view also. For example, patient with metastasis needs a systemic imaging evaluation for the primary and also chemoradiotherapy.

Compared to CT, MRI has a better sensitivity, specificity, PPV, NPV and diagnostic accuracy.

\section{The Limitations of Present Study include}

1. Small study population.

2. Advanced imaging applications such as CT perfusion, MR spectroscopy have not been applied.

\section{REFERENCES}

[1] Merchant TE, Pollack IF, Loeffler JS. Brain tumors across the age spectrum: biology, therapy, and late effects. Semin Radiat Oncol 2010;20(1):58-66.

[2] Harwood-Nash DC. Primary neoplasms of the central nervous system in children. Cancer 1991;67(4 Suppl):1223-8.
[3] Buetow PC, Smirniotopoulos JG, Done S. Congenital brain tumors: a review of 45 cases. AJNR Am J Neuroradiol 1990;11(4):793-9.

[4] Kaderali Z, Lamberti-Pasculli M, Rutka JT. The changing epidemiology of paediatric brain tumours: a review from the hospital for sick children. Childs Nerv Syst 2009;25(7):787-93.

[5] Wemer MH, Phuphanich S, Lyman GH. The increasing incidence of malignant gliomas and primary central nervous system lymphomas in the elderly. Cancer 1995;76(9):1634-42.

[6] DeMonte F, Al-Mefty 0. Meningiomas. In: Kaye AH, Laws ER. (eds). Brain tumors. New York, Churchill Livingstone, 1995:675-704.

[7] Taghipour Zahir SH, Sadrabadi MR, Dehghani F. Evaluation of diagnostic value of CT scan and MRI in brain tumors and comparison with biopsy. Iranian Journal of Pediatric Hematology Oncology 2011;1(4):121-5.

[8] Kendall BE, Jakubowski J, Pullicino P, et al. Difficulties in the diagnosis of supratentorial gliomas by CAT scan. J Neurol Neurosurg Psychiatry 1979;42(6):48592.

[9] Baker HL, Houser OW, Campbell JK. National cancer institute study: evaluation of computed tomography in the diagnosis of intracranial neoplasms. I. Overall results. Radiology 1980;136(1):91-6. 